\title{
Summary of WPT FOA Phase II Demonstration Performed on July 21, 2015
}

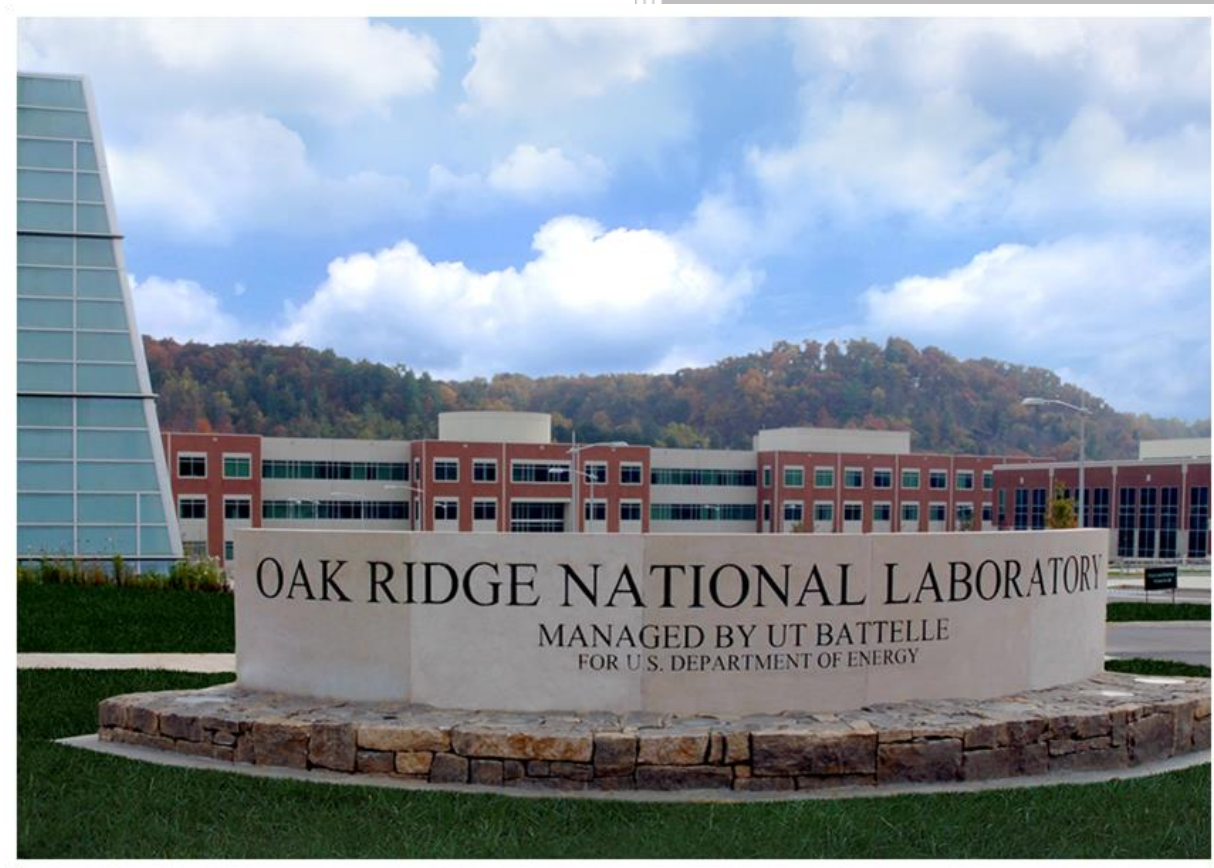

P.T. Jones

August 2015 


\title{
DOCUMENT AVAILABILITY
}

Reports produced after January 1, 1996, are generally available free via US Department of Energy (DOE) SciTech Connect.

Website http://www.osti.gov/scitech/

Reports produced before January 1, 1996, may be purchased by members of the public from the following source:

\author{
National Technical Information Service \\ 5285 Port Royal Road \\ Springfield, VA 22161 \\ Telephone 703-605-6000 (1-800-553-6847) \\ TDD 703-487-4639 \\ Fax 703-605-6900 \\ E-mail info@ntis.gov \\ Website http://www.ntis.gov/help/ordermethods.aspx
}

Reports are available to DOE employees, DOE contractors, Energy Technology Data Exchange representatives, and International Nuclear Information System representatives from the following source:

Office of Scientific and Technical Information

PO Box 62

Oak Ridge, TN 37831

Telephone 865-576-8401

Fax 865-576-5728

E-mail reports@osti.gov

Website http://www.osti.gov/contact.html

This report was prepared as an account of work sponsored by an agency of the United States Government. Neither the United States Government nor any agency thereof, nor any of their employees, makes any warranty, express or implied, or assumes any legal liability or responsibility for the accuracy, completeness, or usefulness of any information, apparatus, product, or process disclosed, or represents that its use would not infringe privately owned rights. Reference herein to any specific commercial product, process, or service by trade name, trademark, manufacturer, or otherwise, does not necessarily constitute or imply its endorsement, recommendation, or favoring by the United States Government or any agency thereof. The views and opinions of authors expressed herein do not necessarily state or reflect those of the United States Government or any agency thereof. 
Energy and Transportation Science Division

\title{
SUMMARY OF WPT FOA PHASE II DEMONSTRATION PERFORMED ON JULY 21, 2015
}

\author{
P.T. Jones \\ Advanced Vehicle Systems Prog. Mgr. \\ Omer Onar \\ Wireless Power Transfer FOA Principle Investigator
}

August 2015

Prepared by OAK RIDGE NATIONAL LABORATORY

Oak Ridge, TN 37831-6283

managed by

UT-BATTELLE, LLC

for the

US DEPARTMENT OF ENERGY

under contract DE-AC05-00OR22725 


\section{CONTENTS}

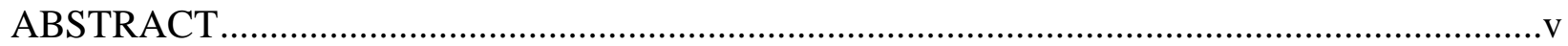

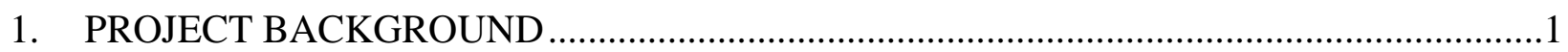

2. PHASE II DEMONSTRATION ACTIVITIES SUMMARY FOR JULY $21,2015 \ldots \ldots \ldots \ldots \ldots . .2$

2.1 WPT Hardware Demonstrations ..............................................................................

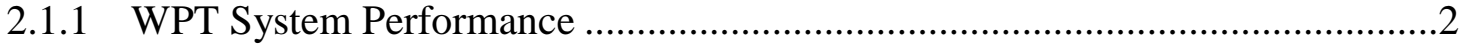

2.1.2 Dynamic WPT Alignment Hardware Demonstration .......................................

2.1.3 Communications Hardware Demonstration ......................................................

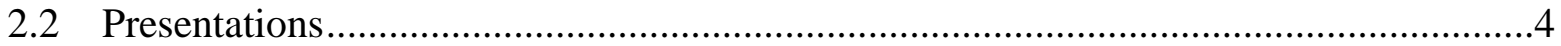

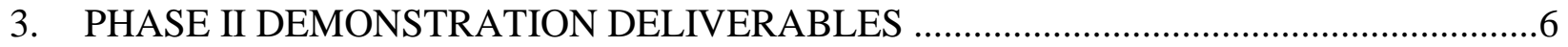

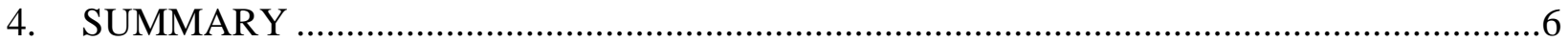




\begin{abstract}
This summary provides details of the activities, presentations and hardware demonstrations performed at the International Transportation Innovation Center (iTiC) in Greenville, South Carolina as deliverables for the wireless power transfer (WPT) FOA \#000667 Phase II gateway. This report does not attempt to identify all encompassing efforts from each of the partners leading up to the demonstration, but will attempt to provide a record which briefly describes the project deliverables met and expectations from the Department of Energy (DOE) as action items agreed to during the wrap-up session on July 21, 2015.
\end{abstract}




\section{PROJECT BACKGROUND}

The Wireless Power Transfer (WPT) technology demonstration Funding Opportunity Announcement (FOA) was intended to raise the level of maturity of WPT charging hardware to near commercial levels and raise the level of understanding and in-use data of the technology for the development of standards which will be used to deploy this technology safely into public use. The Phase II demonstration activity was held to serve as a gateway event, allowing the team members to progress in the final phase of the project once the Department of Energy (DOE) approval was obtained.

This demonstration project uses WPT technology developed at ORNL. The focus of this second phase of the project has been to integrate the ORNL system into currently available gridconnected plug-in electric vehicles (PEVs), and develop the ancillary subsystems on both the vehicle and grid for the system to be evaluated in Phase III.

The various partners in the project had a wide range of responsibilities and deliverable milestones, many of which were performed in parallel to allow for a representative hardware demonstration of the system at the International Transportation Innovation Center (iTiC).

Phase I of this project was completed in November of 2013 and included a demonstration of the power electronics and coupling technology developed by ORNL in a laboratory setting. The project technology requirements of power transfer level of $6.6 \mathrm{~kW}$ and an overall efficiency, from the AC point of connection to DC output on the simulated vehicle side of the system, of $85 \%$ were met in this demonstration.

Phase II of this project focused on establishing required subsystems to enable grid side control and provide the development of the technology when integrated into the project vehicles. The validation testing of the WPT system while operating as an integral part of the OEM supplied program vehicles served as the Phase II gateway for this project. This demonstration activity met the required deliverables for this check point in the project as detailed in this summary.

Phase III of this project will include and focus on testing and evaluation of vehicles that have had the ORNL WPT systems integrated into them. FOA partner Clemson University's International Center for Automotive Research (ICAR) has an established relationship with the iTiC, which will be the sole location for deployed hardware and vehicles developed under the effort supported by this DOE project. 


\section{PHASE II DEMONSTRATION ACTIVITIES SUMMARY FOR JULY 21, 2015}

\subsection{WPT HARDWARE DEMONSTRATIONS}

In an effort to highlight various subsystems and test development equipment required for Phase III evaluations, hardware demonstrations of various subsystems in addition to the vehicles equipped with the WPT system were demonstrated.

\subsubsection{WPT System Performance}

In preparation for the day's events Grid-side Unit \#1 (GSU\#1) and the Toyota supplied Scion iQ, with the WPT system integrated by Evatran, were setup with appropriate power meters and sensors to provide measurements of the system's charging efficiency and power transfer rate (Figures 1a and 1b).

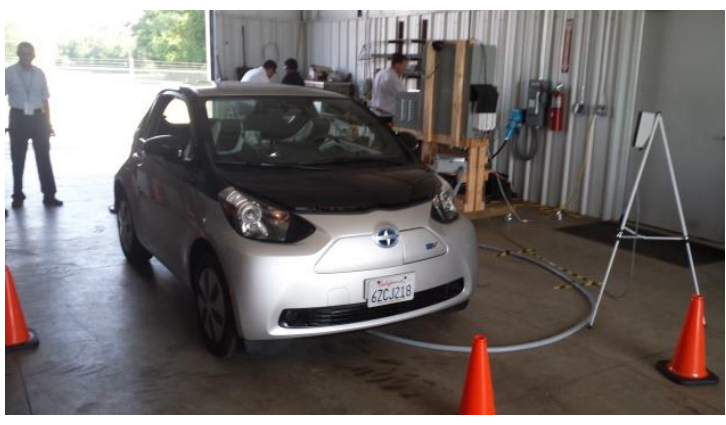

Figure. 1a. Scion iQ pretest.

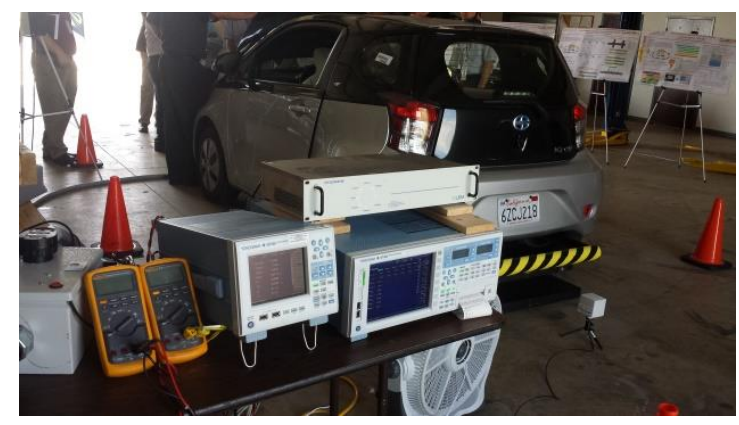

Figure 1b. Efficiency measurement hardware.

During the morning's testing, the system was able to charge the Scion iQ at $6.9 \mathrm{~kW}$ across a $165 \mathrm{~mm}$ air gap and obtain a 85.49\% power transfer efficiency, as seen in Figures $2 \mathrm{a}$ and $2 \mathrm{~b}$. This exceeds the gateway power, efficiency and air gap requirements for the program. However, during this testing some other system parameters were recognized as possible impact parameters for the efficiency of the system.

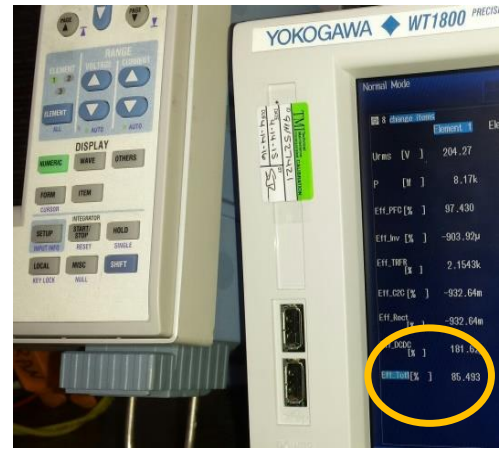

Figure 2a. Yokogawa efficiency measurement.

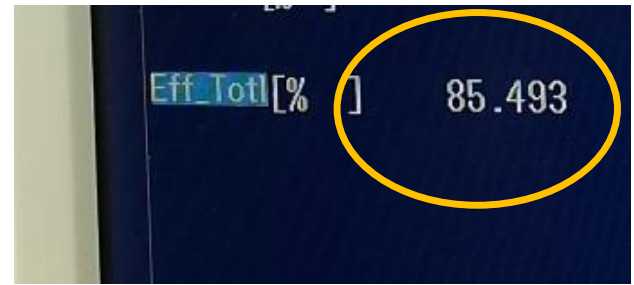

Figure 2b. Zoom in on efficiency measurement.

Later in the morning after the initial project status and discoveries presentations were completed, the attendees moved out to the iTiC building at the South Carolina Technology and Aviation Center (SC-TAC) to observe the first hardware demonstrations. The ambient temperature had 
risen and the available line input voltage (grid voltage) had dropped to $203 \mathrm{~V}$ (the WPT system requirement for input voltage is $208 \mathrm{~V}$ ); as a result the overall system efficiency had dropped to $84.7 \%$, though still at $6.9 \mathrm{~kW}$ and $165 \mathrm{~mm}$ air gap. The DOE representatives agreed that the system met the program requirements, but would require additional information about modifications to the system that would enable consistent high efficiency operation of the WPT system. (That list can be found below in Table 1).

Table 1. Notable Project Improvement Tasks

\begin{tabular}{lll}
\hline Description of Parameter & Required Change & Plans to update \\
\hline $\begin{array}{l}\text { Low Line Voltage at Test } \\
\text { Center }\end{array}$ & $\begin{array}{l}\text { Loaded power rating of 208V } \\
\text { minimum; 220V and 240V levels } \\
\text { are also acceptable. }\end{array}$ & iTiC to follow up \\
\hline $\begin{array}{l}\text { Primary coil high frequency } \\
\text { lead line and other AC wires } \\
\text { too long }\end{array}$ & $\begin{array}{l}\text { Shorten specific coil leads and GSU } \\
\text { input lines for static testing }\end{array}$ & $\begin{array}{l}\text { ORNL to modify one coil lead prior to } \\
\text { shipment to INL }\end{array}$ \\
\hline $\begin{array}{l}\text { Too long 60Hz AC wires from } \\
\text { grid point of connection to the } \\
\text { GSU input }\end{array}$ & Shorten grid side AC wires & $\begin{array}{l}\text { Evatran to shorten the grid side AC } \\
\text { wires. }\end{array}$ \\
\hline $\begin{array}{l}\text { ESS System Voltage } \\
\text { Higher output voltage allows system } \\
\text { to work in boosted power range and } \\
\text { operate more efficiently. *Many } \\
\text { future vehicles are planned to have } \\
\text { higher ESS voltages. }\end{array}$ & $\begin{array}{l}\text { No Change planned, as GSU } \\
\text { components are sized to meet a range } \\
\text { of output voltages for all of the } \\
\text { vehicles in project }\end{array}$ \\
\hline Ambient Temperature & & $\begin{array}{l}\text { This impact will be investigated during } \\
\text { phase III }\end{array}$ \\
\hline
\end{tabular}

A Toyota supplied Plug-in Prius (PIP) was added to the vehicle test fleet to show how the system might interact with a J1772 interface. For this project, Toyota required the WPT system to pass through the vehicle's original equipment manufacturer (OEM) on-board charger (OBC) which meant the power transfer rate was $2.1 \mathrm{~kW}$ nominal and $2.5 \mathrm{~kW}$ maximum, depending on the vehicle request. Additional power electronics were also required to enable the $\mathrm{OBC}$ of the Prius to function with a wireless setup. ORNL provided final integration components and met the challenge of repairing Grid-Side unit \#2 (GSU\#2) in time for the demonstration (Figure 3). Though there was an issue with the alignment sensors on the vehicle, the system was able to charge at $2.1 \mathrm{~kW}$ power transfer rate once alignment was obtained.

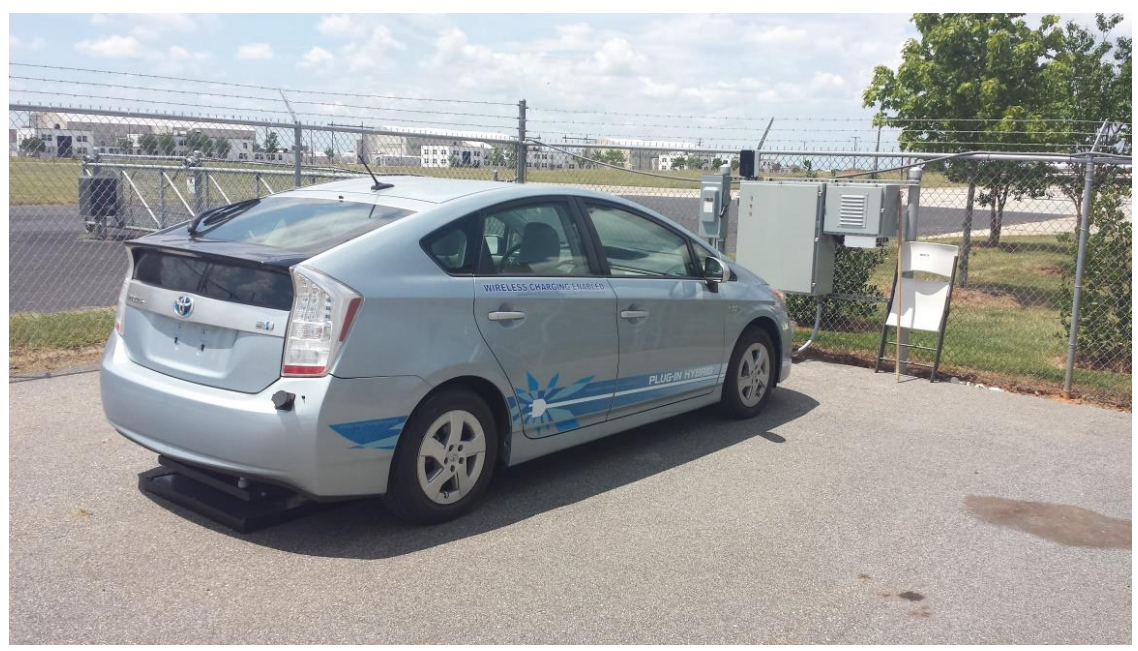

Figure 3. Wireless charging of a Plug-in Prius. 


\subsubsection{Dynamic WPT Alignment Hardware Demonstration}

During the Phase II demonstration at iTiC, ICAR representatives demonstrated the alignment method planned for the in-motion wireless testing activities. Representatives from the DOE and National Energy Technology Laboratory (NETL) were taken around the test track facility at iTiC and then given a chance to go thru the process of aligning a vehicle for a dynamic wireless power transfer test. The demonstration utilized a RAV4 EV similar to the vehicles that are currently being integrated with power electronics to enable dynamic WPT and interact with the testbed at iTiC. The video alignment method requires the drivers to attain a set speed, engage cruise control, and then align the vehicle for a test run. In the future it is likely that a form of autonomous driving would align the vehicle for best dynamic wireless charging performance. However, since those systems are in short supply, the ICAR students have created a method to increase the repeatability of the on-site dynamic testing which will be performed on two RAV4 EVs in Phase III.

\subsubsection{Communications Hardware Demonstration}

During the Phase II demonstration at iTiC, ICAR and Cisco representatives demonstrated the wireless communications subsystem used for the project, as well as linking in additional research being performed in this area.

The communications demonstration included the selection criteria for the dedicated short-range communications (DSRC) equipment, some fundamental description of the prototype Cisco hardware and logic for utilizing DSRC technology versus a simpler Bluetooth or other wireless communication system for this project.

This presentation then turned into a hardware demonstration, as the real time interaction and data collection of a vehicle operating at iTiC in Greenville, South Carolina was displayed through a graphical data on an information server in Cisco's California office, thru a web link. The system highlighted the importance of vehicle to grid connectivity which will be required for in-motion power transfer, and is also valuable for stationary charging applications.

\subsection{PRESENTATIONS}

Numerous presentations were included in the event to update the DOE/NETL representatives on the project progress and the challenges that had been worked through to integrate the technology demonstrated during the Phase I gateway, into the Toyota supplied vehicles.

Due to changes in project partners (earlier another OEM was to supply vehicles in addition to the Toyota vehicles) Toyota increased their support of the project by offering four vehicles in total to the project. The largest impact of the new vehicles was a change in the protocols which the WPT technology had to interact with. The lessons learned in this development will be put into a presentation to the Society of Automotive Engineers (SAE) J2954 committee. The work performed under this FOA represents some of the first instances of a WPT system that has met protocol requirements of both J1772 and CHAdeMO equipped vehicles. 
Additional presentations were given which identified opportunities for cost reduction both in the WPT system and the communications subsystem. The Phase II activities reports will include the business case, as well as the final draft of the Phase III Test and Evaluation Plan. 


\section{PHASE II DEMONSTRATION DELIVERABLES}

Summary of WPT system performance:

GSU\#1 testing with Scion iQ

- Integrated system met DOE project goals of 85\% efficiency from Grid to ESS at $160 \mathrm{~mm}$ air gap and a $6.6 \mathrm{~kW}$ power transfer rate. (System actually exceeded air gap, $165 \mathrm{~mm}$ and power transfer rate, $6.9 \mathrm{~kW}$ )

- System successfully met CHAdeMO protocols to allow WPT charging of vehicle from $20 \%$ SOC to $80 \%$ (These SOC limits are held in the CHAdeMO protocol).

- Confirming wireless communications requirements for a CHAdeMO system.

GSU\#2 testing with Plug-in Prius

- System operated wirelessly through OBC using J1772 protocols at $2.1 \mathrm{~kW}$ power transfer rate.

- Confirming wireless communications meeting J1772 requirements.

- Outdoors location of testing apparatus will enable ambient temperature characterization of system.

\section{SUMMARY}

The demonstration successfully showed the integration of the ORNL WPT system into two vehicles of the project fleet. In total there will be five test vehicles for the project. The two additional Toyota vehicles are currently at ORNL and the integration process has begun. The final vehicle will be the Evatran supplied Chevy Volt with a moveable vehicle side receiving coil. This vehicle will be used to investigate ease of alignment under various driving conditions and operator sensitivity to coil position.

The program requirements for power transfer rate, air gap, and transfer efficiency were met on the Scion iQ. Additional testing will be completed prior to shipping a vehicle and system to Idaho National Laboratory in September.

Phase II reports are in process and will be forwarded to DOE and NETL in August, 2015. 